\title{
Effect of Mobile Device-Assisted N-of-1 Trial Participation on Analgesic Prescribing for Chronic Pain: Randomized Controlled Trial
}

\author{
David D. Odineal, $M D^{1,2}$, Maria T. Marois, $P h D, M P H^{3}$, Deborah Ward, $P h D, R N^{4}$, \\ Christopher H. Schmid, $P h D^{5,6}$, Rima Cabrera, $M S W^{3}$, Ida Sim, $P h D, M D^{7,8}$, \\ Youdan Wang, MS ${ }^{5}$, Barth Wilsey, MD 9,10 , Naihua Duan, $P h D^{17}$, Stephen G. Henry, MD ${ }^{12}$, \\ and Richard L. Kravitz, MD, MSPH ${ }^{12}$
}

\begin{abstract}
'Department of Medicine, Madigan Army Medical Center, Joint Base Lewis McChord, Tacoma, WA, USA; ${ }^{2}$ School of Medicine, University of California Davis, Sacramento, CA, USA; ${ }^{3}$ Center for Health Care Policy and Research, University of California Davis, Sacramento, CA, USA; ${ }^{4}$ Betty Irene Moore School of Nursing, University of California Davis, Sacramento, CA, USA; ${ }^{5}$ Department of Biostatistics, Brown University School of Public Health, Providence, RI, USA; ${ }^{6}$ Center for Evidence Synthesis in Health, Brown University School of Public Health, Providence, RI, USA; ${ }^{7}$ Division of General Internal Medicine, University of California San Francisco, San Francisco, CA, USA; ${ }^{8}$ Open mHealth, New York, NY, USA; ${ }^{9}$ Veterans Affairs Northern California Health Care System, Sacramento Medical Center, Mather, CA, USA; ${ }^{10}$ Department of Psychiatry, University of California, San Diego, CA, USA; " 'Department of Psychiatry, Columbia College of Physicians and Surgeons, New York, NY, USA; ${ }^{2}$ Department of Internal Medicine, Division of General Medicine, University of California Davis, Sacramento, CA, USA.
\end{abstract}

OBJECTIVES: Opioids and non-steroidal anti-inflammatory drugs (NSAIDs) are frequently prescribed for chronic musculoskeletal pain, despite limited evidence of effectiveness and well-documented adverse effects. We assessed the effects of participating in a structured, personalized self-experiment ("N-of-1 trial") on analgesic prescribing in patients with chronic musculoskeletal pain.

METHODS: We randomized 215 patients with chronic pain to participate in an N-of- 1 trial facilitated by a mobile health app or to receive usual care. Medical records of participating patients were reviewed at enrollment and 6 months later to assess analgesic prescribing. We established thresholds of $\geq 50, \geq 20$, and $>0$ morphine milligram equivalents (MMEs) per day to capture patients taking relatively high doses only, patients taking lowmoderate as well as relatively high doses, and patients taking any dose of opioids, respectively.

RESULTS: There was no significant difference between the N-of- 1 and control groups in the percentage of patients prescribed any opioids (relative odds ratio (ROR) = 1.05; $95 \%$ confidence interval $[\mathrm{CI}]=0.61$ to $1.80, p=$ 0.87). There was a clinically substantial but statistically not significant reduction of the percentage of patients receiving $\geq 20 \mathrm{MME}(\mathrm{ROR}=0.58 ; 95 \% \mathrm{CI}=0.33$ to 1.04 , $p=0.07$ ) and also in the percentage receiving $\geq 50 \mathrm{MME}$ $(\mathrm{ROR}=0.50 ; 95 \% \mathrm{CI}=0.19$ to $1.34, p=0.17)$. There was a significant reduction in the proportion of patients in the N-of-1 group prescribed NSAIDs compared with control (relative odds ratio $=0.53 ; 95 \% \mathrm{CI}=0.29$ to $0.96, p=0.04$ ), with no concomitant increase in average pain intensity.

Electronic supplementary material The online version of this article (https://doi.org/10.1007/s11606-019-05303-0) contains supplementary material, which is available to authorized users.

Received March 2, 2019

Revised July 3, 2019

Accepted August 6, 2019

Published online August 28, 2019
There was no significant change in use of adjunctive medications (acetaminophen, gabapentenoids, or topicals).

DISCUSSION: These exploratory results suggest that participation in $\mathrm{N}$-of-1 trials may reduce long-term use of NSAIDs; there is also a weak signal for an effect on use of opioids. Additional research is needed to confirm these results and elucidate possible mechanisms.

TRIAL REGISTRATION: ClinicalTrials.gov Identifier: NCT02116621.

KEY WORDS: N-of-1 trials; chronic pain; non-steroidal anti-inflammatory agent; opioid; analgesic.

J Gen Intern Med 35(1):102-11

DOI: $10.1007 / \mathrm{s} 11606-019-05303-0$

(c) Society of General Internal Medicine 2019

\section{INTRODUCTION}

Chronic musculoskeletal pain is a vexing clinical problem. Most pharmacological treatments produce modest benefits accompanied by significant potential for harm. ${ }^{1,2}$ In particular, long-term use of opioids has been reliably associated with development of physical and psychological dependence, sometimes leading to substance use disorder and rarely to accidental overdose and death. ${ }^{3-5}$ While high doses convey the greatest risk, no dose is risk-free. ${ }^{6}$ Furthermore, opioids have not been consistently shown to provide better analgesia than non-opioid pain medications for non-cancer related chronic pain. ${ }^{2,}$ 7, 8 Yet simply replacing opioids with nonsteroidal anti-inflammatory drugs (NSAIDs), which are arguably the most effective pharmacologic alternative for chronic musculoskeletal pain, poses other risks, including nephrotoxicity, gastrointestinal bleeding, and heart failure. ${ }^{9-14}$ Clinicians and patients need approaches to analgesic prescribing that maximize pain relief while minimizing potential harms. 
In typical practice, clinicians try multiple pharmacologic and non-pharmacologic approaches to chronic musculoskeletal pain, advancing by trial and error, with outcomes usually assessed for the interval between office visits through informal questioning. There are two problems with this approach. First, perceived benefits over a single interval may be influenced by myriad external factors including random fluctuations in the underlying painful condition, physical activity, comorbid medical conditions, stress, finances, and weather. ${ }^{15-18}$ Second, global assessments of benefits and harms as determined by simple questioning (e.g., "do you think the medication helped?") are subject to recall bias. ${ }^{19}$ As a result, the "trial of therapy" approach is a crude instrument for identifying the treatment regimen most likely to deliver net benefits for a particular patient in the long term. The missing element is replication: comparing a treatment to its alternative (which may include no treatment) more than once.

N-of-1 trials - rigorous crossover experiments conducted within a single patient - offer a solution. In an N-of-1 trial, treatment periods (i.e., the time periods when patients are tasked with following regimen A versus regimen B) may be assigned in random order or in a predetermined, counterbalanced fashion (e.g., ABABAB or ABBA). Outcomes while on each treatment regimen are recorded systematically. Following the trial, graphical, or statistical reports provide a direct comparison of treatment effects. The general approach is schematized in Fig. 1, modified from Zucker et al. ${ }^{20,21}$ In chronic musculoskeletal pain, N-of-1 trial-based prescribing has the potential to reduce unnecessary opioid and NSAID use by demonstrating the superiority or equivalence of potentially safer treatments such as acetaminophen, topical agents, and (in more limited circumstances) gabapentenoids (collectively termed "adjunctive treatments") for the individual patient. ${ }^{22}$

It has been suggested that N-of-1 trials might improve patient outcomes through both biopsychosocial and pharmacologic mechanisms. The biopsychosocial pathway may operate through expanded patient participation in care. Previous research has shown that more active patient involvement may lead to greater self-efficacy, better adherence to therapy, and improvement in health outcomes. ${ }^{23,} 24$ In contrast, the pharmacologic pathway is hypothesized to work by nudging patients and prescribers towards medication regimens that are more effective or better tolerated.

In the Personalized Research for Monitoring Pain Treatment (PREEMPT) Study, 215 patients with chronic musculoskeletal pain were randomized to receive care as usual or to participate in an N-of-1 trial co-designed with their clinician. ${ }^{25,}{ }^{26} \mathrm{We}$ recently reported that compared with 107 patients receiving usual care, the 108 patients randomized to the N-of-1 group reported better medication-related shared decision-making but experienced no greater improvement in pain-related impairment at 6 months. ${ }^{26}$ However, that report did not include more recently obtained medical record data on analgesic prescribing at baseline and 6 months follow-up. In the current study, we examined electronic health records of the 190 patients who both granted us permission to do so and who completed 6-month follow-up, focusing on the extent to which participation in $\mathrm{N}$ of-1 trials (versus usual care) was associated with changes in opioid, NSAID, and adjunctive treatment prescribing.

\section{METHODS}

The Trialist mobile app reminded patients randomized to the $\mathrm{N}$ of-1 arm to switch periodically between treatment regimens and to record pain daily pain-related outcomes. The current report explores whether participation in an N-of-1 trial using the Trialist app (compared with usual care) led to changes in the prescription of opioids, NSAIDs, and "adjunctive treatments" (defined to include acetaminophen, gabapentenoids, and topical agents) over approximately 6 months. Opioids and NSAIDs have well-described harms - and in the case of opioids, uncertain benefits - when used for chronic pain. The evidence on effectiveness of acetaminophen, gabapentenoids, and topical agents is equally uncertain, but safety concerns are somewhat reduced. ${ }^{27-}$

32 The study was approved by the Institutional Review Boards at the University of California, Davis (\#496804) and the Veterans Affairs Northern California Health Care System (VANCHCS) (\#13-12-00717). Further methodological details are available in articles by Barr et al. ${ }^{25}$ and by Kravitz et al. ${ }^{26}$

\section{Recruitment of Clinicians and Patients}

The study recruited clinicians and patients within the University of California, Davis (UC Davis) Primary Care Network (PCN), UC Davis Family Medicine Clinic, UC Davis General Medicine Clinic, and Veterans Administration Northern California Health Care System (VANCHCS). Clinicians were recruited through email and in-person presentations. In total, 48 clinicians practicing in primary care settings agreed to participate including 44 physicians, one nurse practitioner, two physician assistants, and one clinical pharmacist. Participating clinicians received limited reimbursement for their extra study-related time.

Patients visiting participating practices with a chronic musculoskeletal pain diagnosis (as identified by scanning administrative records for appropriate ICD-9 diagnostic codes) within the past 6 months were sent a letter describing the study and inviting them to participate. Patients contacting the study office ( $n=1092$ ) were screened for eligibility over the telephone; medical eligibility was confirmed with the patient's primary clinician. All participants were English-speaking, 18-75 years of age, owned an eligible smartphone or tablet, and experienced chronic musculoskeletal pain rated 4 or higher on at least one item of the pain intensity, enjoyment of life, and general activity (PEG) scale. ${ }^{33}$ Treating clinicians confirmed that the patient had pain potentially amenable to treatment with acetaminophen, nonsteroidal anti-inflammatory drugs (NSAIDs), low-dose (short-acting) opioids, a complementary/alternative treatment such as massage or meditation, or a simple combination of these treatments. Patients were excluded if they had 


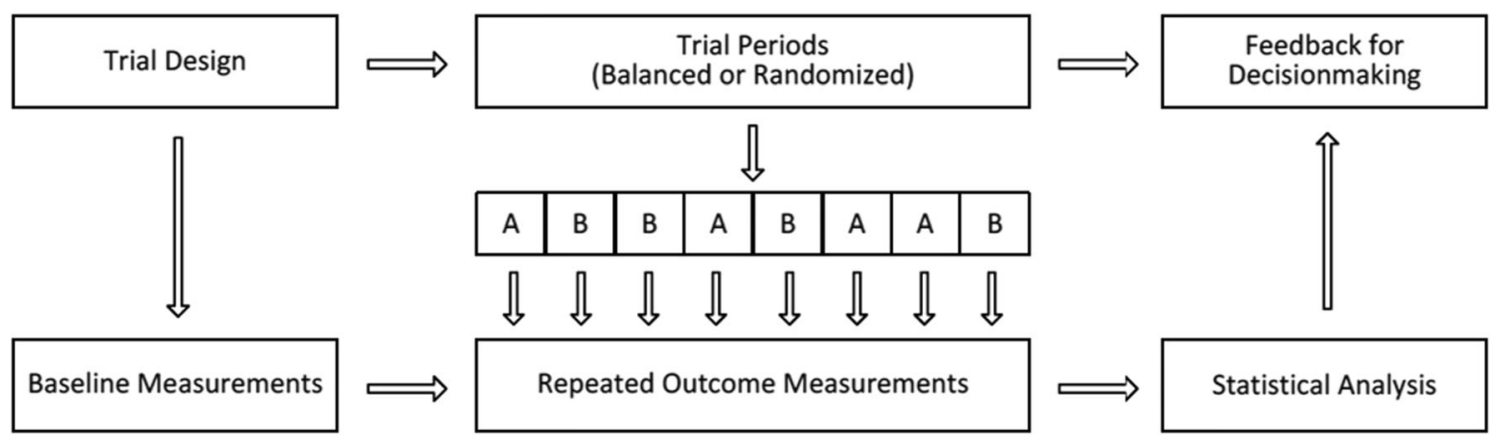

Figure 1 General design for participants randomized to the N-of-1 arm of the PREEMPT Study. Each patient who was randomized to the N-of1 trial arm switched between analgesic regimens at prespecified intervals with the aid of the mobile device application. When the $\mathrm{N}-0 \mathrm{f}-1$ trial was completed, the data collected throughout the course of the trial was considered along with the baseline measurements taken prior to the trial and was used for shared decision-making when determining subsequent optimal pain treatment for the patient.

limited life expectancy $(<2$ years); had treatment for cancer within the last 5 years; were pregnant or breastfeeding; exhibited evidence of alcohol or drug abuse; had a serious mental health condition such as dementia, bipolar disorder, schizophrenia, or depression with active suicidality; or had failed five or more analgesic medications.

Of 1092 patients assessed for eligibility, 732 did not meet inclusion criteria, 145 were eligible but not randomized, and 215 were randomized (108 to the intervention group, 107 to control) (Fig. 2). Chart abstraction was completed for 190 patients (97 intervention, 93 control). Charts were not abstracted for 25 patients either because they failed to provide HIPAA authorization $(n=11)$ or withdrew or were lost to follow-up prior to 6 months $(n=14)$. A comparison of characteristics of patients whose medical records were abstracted to those whose records were not abstracted can be found in Online Appendix Table 1.

Patients randomized to the control arm received usual care. Patients randomized to the N-of-1 arm met with their clinician to co-design a personalized (N-of-1) trial. Both groups completed surveys at $0,3,6$, and 12 months.

Patients randomized to the N-of-1 group worked with their clinician to select (on a desktop computer in the clinician's office) two regimens for comparison from 8 treatment categories $^{1}$ : acetaminophen ${ }^{2}$; any nonsteroidal anti-inflammatory drug $^{3}$; acetaminophen/codeine ${ }^{4}$; acetaminophen/hydrocodone ${ }^{5}$; acetaminophen/oxycodone ${ }^{6}$; tramadol ${ }^{7}$; complementary/ alternative treatments such as massage, meditation, or physical exercise; or $^{8}$ current ongoing therapy (or no therapy). ${ }^{19,20}$ Shortacting opioids were included as options because they are in common use in primary care and because it was believed that some patients might benefit from eliminating them. ${ }^{2}$

In the N-of-1 arm, the treatment regimens to be compared (e.g., treatment A and treatment B) could be single agents (e.g., acetaminophen) or combinations (e.g., acetaminophen plus tramadol). Trials could be structured to compare treatments between categories (e.g., acetaminophen vs acupuncture) or treatments within category (e.g., massage vs yoga). Patientclinician dyads also chose the duration of each treatment period ( 2 weeks when the comparison involved opioids; 1 or 2 weeks when the comparison did not involve opioids), the number of paired comparisons $(2,3$, or 4$)$, and the start date. Trials could last $4,6,8$, or 12 weeks. For example, in an N-of-1 trial comparing tramadol (regimen $\mathrm{A}$ ) with tramadol plus acupuncture (regimen B), the patient might be assigned to an ABBAAB schedule with each period lasting 2 weeks; thus, the total trial duration of this hypothetical trial would be 12 weeks.

Trial parameters were sent to the Trialist system (an open source mobile application, supported by a server-based "backend") on the patient's mobile device. The system randomly chose a counterbalanced treatment sequence; alerted the patient when to begin each treatment; and sent a daily questionnaire asking about pain on average, pain interference with enjoyment of life, and pain interference with daily activities, as well as 5 potential side effects of treatment (drowsiness, fatigue, constipation, sleep problems, and cognitive impairment). Details on the selection criteria for subjects, as well as the functionality of the Trialist app are available elsewhere. ${ }^{26,34}$ Over-the-counter medications were neither regulated nor abstracted in either group.

\section{Patient Characteristics}

Patient characteristics (including age, gender, marital status, race, employment status, education level, experience with mobile devices, and Wi-Fi use) were obtained from selfadministered questionnaires completed at enrollment during the baseline visit with the study clinician. Pain characteristics and medical history were abstracted from progress notes, as well as the "problem list" section of the electronic medical record. Pain was characterized in terms of location, mechanistic category (fibromyalgia, mechanical, inflammatory, and/or neuropathic), and numeric severity score (0-10 point scale). Patients were sorted into categories of "current," "former," or "never/no data" for history of alcohol abuse, prescription drug abuse, recreational drug abuse, tobacco use, and marijuana use.

\section{Opioid and NSAID Prescription Review}

Two co-authors (DO, RC) gathered information on the opioid and non-opioid analgesics patients were taking at the baseline visit and at 6-month follow-up. For follow-up care, we searched 


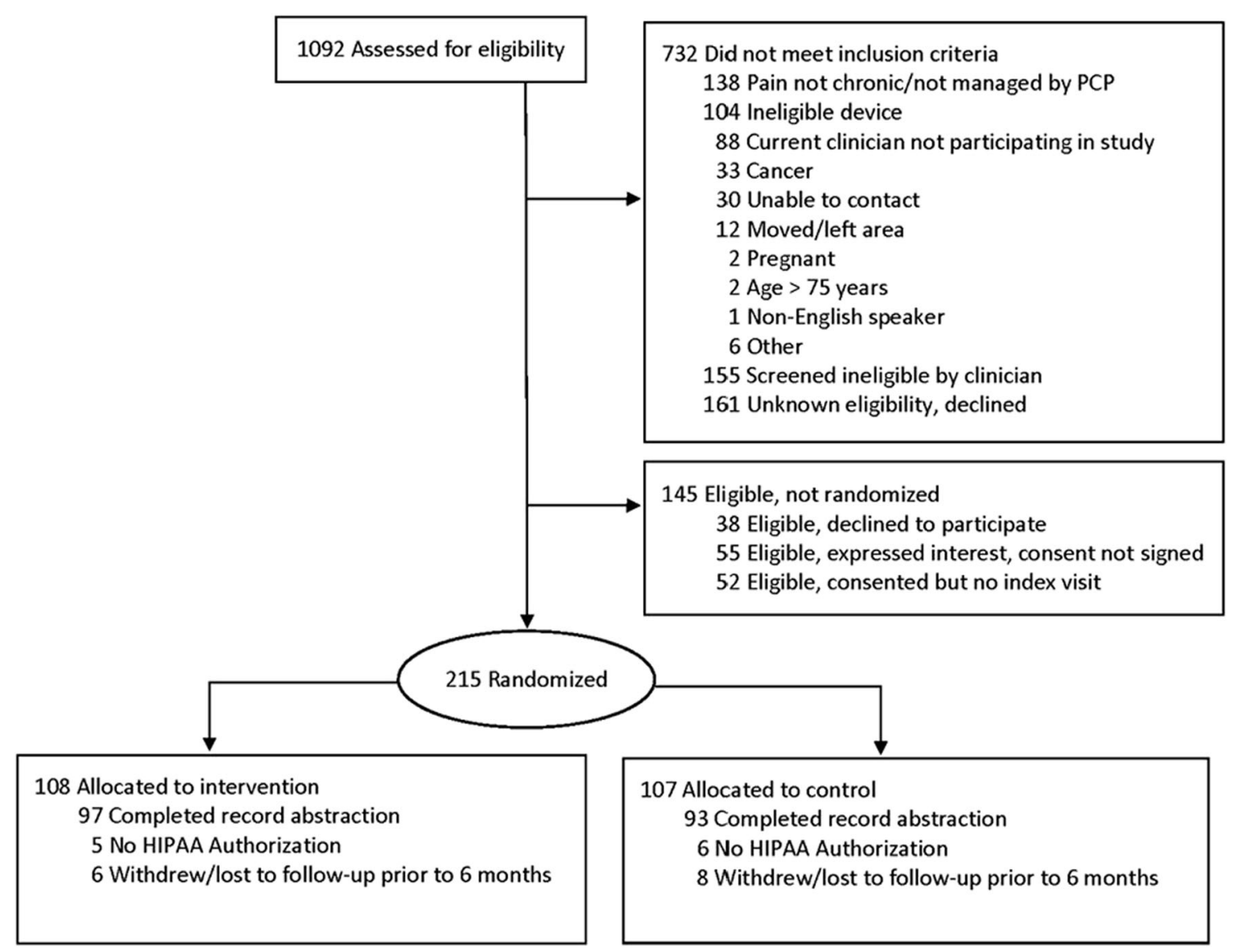

Figure 2 A CONSORT diagram for PREEMPT Study enrollment and inclusion in medical record abstraction. Patients who did not provide HIPAA authorization were not included in medical records abstraction. Patients who informed study personnel that they no longer wished to continue in the study were classified as withdrawals. Patients who could not be located and did not return a survey at the follow-up time point were classified as "lost to follow-up." For patients who withdrew or were lost to follow-up prior to 6 months, medical records were not abstracted.

for evidence of an encounter with the study clinician as close as possible to 26 weeks from the baseline visit, with an acceptable range of 20 to 32 weeks. If no primary care progress note or phone note from the primary care physician existed within the window, a progress note from any specialty was substituted. If the patient had no progress notes or phone notes from any specialty within the 20-32 week window, the active medication list as of 26 weeks after the baseline visit was used to identify current prescriptions. We only abstracted information on prescriptions that were active at the start of the baseline or follow-up visit. For example, a patient who was taking hydrocodone 1 day prior to the 6-month visit and ibuprofen 1 day after the visit would be counted as taking hydrocodone at the time of the 6-month visit. When dosing was ambiguous, the maximum allowable dosage at the most frequent interval allowed by the prescription was used. This calculation is analogous to the method routinely employed by pharmacies to estimate "days supply" of medication. ${ }^{35}$

For opioids, abstracted fields included name of medication, amount per dispensed unit, route of administration, length of prescription, and number of pills per prescription. At each time point, morphine milligram equivalents (MMEs) per day were calculated for patients taking opioids (which included codeine, hydrocodone, oxycodone, morphine, and tramadol) using the conversion formulae applied by Von Korff et al. ${ }^{36}$
For NSAIDs, acetaminophen, and gabapentenoids, abstracted elements included name of the medication, amount per dispensed unit (in $\mathrm{mg}$ or $\mu \mathrm{g}$ ), number of units (e.g., pills) per prescribed dose, maximum frequency per day, scheduled versus as needed (prn), and route of administration. Topical NSAIDs such as topical diclofenac were examined separately. A list of all non-opioid medications that were abstracted may be found in Online Appendix 2.

\section{Interrater Reliability}

Two trained data collectors (DO, RC) independently abstracted information from the same 21 patient medical records. Overall, there was a high level of agreement between abstractors, with perfect agreement on the majority of items. Individual item kappa statistics ranged from 0.70 to 1.0 with an average reliability (kappa) of 0.97 (See Online Appendix 3 for item-specific kappas). The remaining records were each coded by one data collector.

\section{Statistical Analysis}

A marginal generalized linear model implemented with generalized estimating equations (GEE) was used to compare the proportion of patients in the intervention and control groups taking NSAIDs; 
Table 1 Baseline Characteristics of PREEMPT Study Participants with Medical Record Abstraction by Treatment Group

\begin{tabular}{|c|c|c|c|}
\hline Characteristic & $\begin{array}{l}\text { Overall } \\
(N=190) \\
n(\%)\end{array}$ & $\begin{array}{l}\text { N-of-1 } \\
(N=97) \\
n(\%)\end{array}$ & $\begin{array}{l}\text { Control } \\
(N=93) \\
n(\%)\end{array}$ \\
\hline Age, mean (SD), years & $55.4(11.0)$ & $55.5(12.0)$ & $55.3(10.1)$ \\
\hline \multicolumn{4}{|l|}{ Gender } \\
\hline Male & $100(52.6 \%)$ & $52(53.6 \%)$ & $48(51.6 \%)$ \\
\hline Female & $90(47.4 \%)$ & $45(46.4 \%)$ & $45(48.4 \%)$ \\
\hline \multicolumn{4}{|l|}{ Marital status } \\
\hline Married/living with partner & $128(67.4 \%)$ & $67(69.1 \%)$ & $61(65.6 \%)$ \\
\hline Widowed & $9(4.7 \%)$ & $4(4.1 \%)$ & $5(5.4 \%)$ \\
\hline Separated/divorced & $37(19.5 \%)$ & $19(19.6 \%)$ & $18(19.4 \%)$ \\
\hline Never married & $16(8.4 \%)$ & $7(7.2 \%)$ & $9(9.7 \%)$ \\
\hline \multicolumn{4}{|l|}{ Race* } \\
\hline White & $136(71.6 \%)$ & $64(66.0 \%)$ & $72(77.4 \%)$ \\
\hline Black/African American & $25(13.2 \%)$ & $12(12.4 \%)$ & $13(14.0 \%)$ \\
\hline Asian & $12(6.3 \%)$ & $8(8.3 \%)$ & $4(4.3 \%)$ \\
\hline Other & $17(9.0 \%)$ & $13(13.4 \%)$ & $4(4.3 \%)$ \\
\hline Latino/Hispanic & $21(11.1 \%)$ & $13(13.5 \%)$ & $8(8.6 \%)$ \\
\hline \multicolumn{4}{|l|}{ Education } \\
\hline Some HS, no diploma/completed HS or GED & $15(7.9 \%)$ & $4(4.1 \%)$ & $11(11.8 \%)$ \\
\hline Some college/associate degree/vocational training & $94(23.2 \%)$ & $50(51.6 \%)$ & $44(47.3 \%)$ \\
\hline Bachelor degree & $47(24.7 \%)$ & $27(27.8 \%)$ & $20(21.5 \%)$ \\
\hline Master/doctoral/professional degree & $34(17.9 \%)$ & $16(16.5 \%)$ & $18(19.4 \%)$ \\
\hline \multicolumn{4}{|l|}{ Employment } \\
\hline Full time & $80(42.1 \%)$ & $41(42.3 \%)$ & $39(41.9 \%)$ \\
\hline Part time & $15(7.9 \%)$ & $7(7.2 \%)$ & $8(8.6 \%)$ \\
\hline Retired/unable/not employed & $95(50.0 \%)$ & $49(50.5 \%)$ & $46(49.5 \%)$ \\
\hline \multicolumn{4}{|l|}{ Site } \\
\hline UC Davis/Primary Care Network (PCN) & $103(54.2 \%)$ & $52(53.6 \%)$ & $51(54.8 \%)$ \\
\hline Veterans Administration & $87(45.8 \%)$ & $45(46.4 \%)$ & $42(45.2 \%)$ \\
\hline \multicolumn{4}{|l|}{ Tobacco smoking } \\
\hline Current & $14(7.4 \%)$ & $10(10.3 \%)$ & $4(4.3 \%)$ \\
\hline Former & $70(36.8 \%)$ & $32(33.0 \%)$ & $38(40.9 \%)$ \\
\hline Never & $106(55.8 \%)$ & $55(56.7 \%)$ & $51(54.8 \%)$ \\
\hline \multicolumn{4}{|l|}{ Alcohol problem } \\
\hline Current (diagnosis of alcoholism or problem drinking, or $\geq 3$ drinks/day) & $3(1.6 \%)$ & $2(2.1 \%)$ & $1(1.1 \%)$ \\
\hline Former & $14(7.4 \%)$ & $5(5.2 \%)$ & $9(9.7 \%)$ \\
\hline Never & $173(91.1 \%)$ & $90(92.8 \%)$ & $83(89.3 \%)$ \\
\hline \multicolumn{4}{|l|}{ Pain category ${ }^{\dagger}$} \\
\hline Mechanical & $166(87.4 \%)$ & $83(85.6 \%)$ & $83(89.3 \%)$ \\
\hline Fibromyalgia* & $8(4.2 \%)$ & $2(2.1 \%)$ & $6(6.5 \%)$ \\
\hline Inflammatory & $4(2.1 \%)$ & $3(3.1 \%)$ & $1(1.1 \%)$ \\
\hline Neuropathic & $28(14.7 \%)$ & $15(15.5 \%)$ & $13(14.0 \%)$ \\
\hline Pain intensity at baseline, mean (SD) & $53.5(5.2)$ & $53.6(5.4)$ & $53.5(5.0)$ \\
\hline Pain intensity at 6 months follow-up, mean (SD) & $51.3(6.0)$ & $50.5(6.6)$ & $52.2(5.2)$ \\
\hline Baseline opioid use (any use) & $86(45.3 \%)$ & $41(42.3 \%)$ & $45(48.4 \%)$ \\
\hline Baseline opioid use, mean MME (SD) & $13.3(28.0)$ & $13.1(29.9)$ & $13.4(26.1)$ \\
\hline Baseline NSAID use & $81(42.6 \%)$ & $49(50.5 \%)$ & $32(34.4 \%)$ \\
\hline \multicolumn{4}{|l|}{ Active medical diagnoses } \\
\hline Sleep apnea & $38(20.0)$ & $19(19.6 \%)$ & $19(20.4 \%)$ \\
\hline $\mathrm{COPD}^{*}$ & $9(4.7 \%)$ & $7(7.2 \%)$ & $2(2.2 \%)$ \\
\hline History of peptic ulcer disease/GI bleeding past 5 years* & $2(1.1 \%)$ & 0 & $2(2.2 \%)$ \\
\hline Chronic kidney disease (CKD stage III or greater) & $8(4.2 \%)$ & $6(6.2 \%)$ & $2(2.2 \%)$ \\
\hline Congestive heart failure & $7(3.7 \%)$ & $5(5.2 \%)$ & $2(2.2 \%)$ \\
\hline Diabetes & $36(19.0 \%)$ & $21(21.7 \%)$ & $15(16.1 \%)$ \\
\hline \multicolumn{4}{|l|}{ Active psychiatric diagnoses } \\
\hline Depression & $60(31.6 \%)$ & $32(33.0 \%)$ & $28(30.1 \%)$ \\
\hline PTSD & $23(12.1 \%)$ & $11(11.3 \%)$ & $12(12.9 \%)$ \\
\hline Insomnia & $29(15.3 \%)$ & $14(14.4 \%)$ & $15(16.1 \%)$ \\
\hline Other anxiety disorder & $26(13.7 \%)$ & $12(12.4 \%)$ & $14(15.1 \%)$ \\
\hline \multicolumn{4}{|l|}{ Concomitant Medications } \\
\hline Benzodiazepines (any dose) $)^{\ddagger}$ & $22(11.6 \%)$ & $7(7.2 \%)$ & $15(16.1 \%)$ \\
\hline Aspirin or anticoagulant therapy & $44(23.2 \%)$ & $21(21.7 \%)$ & $23(24.7 \%)$ \\
\hline
\end{tabular}

*Differences between $N$-of-1 and control group, $0.05<p \leq 0.1$

${ }^{t}$ Patients could be classified with more than one category of pain

${ }^{*}$ Differences between $N$-of- 1 and control group, $p \leq 0.05$

opioids (with dosing thresholds of $>0 \mathrm{MME} /$ day (indicating any opioid use), $\geq 20 \mathrm{MME}$ per day, or $\geq 50 \mathrm{MME} /$ day); and "adjunctive medications" (acetaminophen, gabapentenoids, and topicals; first considered separately, then together). The model included fixed effects for time (baseline or 6 months), study arm (intervention or control), and an interaction term for time by arm. The interaction term was estimated as a relative odds ratio (ROR) which assessed the extent to which changes in analgesic prescribing over 6 months differed between groups. All statistical analyses were performed using the R software (version 3.3.1; R Foundation). 
Table 2 Change Between Baseline Visit and 6-Month Follow-Up in Use of Opioids

\begin{tabular}{|c|c|c|c|c|c|c|c|c|c|}
\hline $\begin{array}{l}\text { Dose } \\
\text { threshold }\end{array}$ & Group & Number & $\begin{array}{l}\text { Never taking (or } \\
\text { below dose } \\
\text { threshold)* }\end{array}$ & $\begin{array}{l}\text { Continued } \\
\text { taking at or } \\
\text { above } \\
\text { threshold }^{\dagger}\end{array}$ & $\begin{array}{l}\text { Started taking } \\
\text { at or above } \\
\text { threshold }\end{array}$ & $\begin{array}{l}\text { Stopped taking } \\
\text { or dropped } \\
\text { below } \\
\text { threshold }^{\S}\end{array}$ & $\begin{array}{l}\text { OR } \\
(95 \% \\
\text { CI })^{9}\end{array}$ & $\begin{array}{l}\text { ROR } \\
\text { (95\% } \\
\text { CI) }\end{array}$ & $\begin{array}{l}p \\
\text { value }\end{array}$ \\
\hline \multirow[t]{2}{*}{$>0 \mathrm{MME}$} & N-of-1 & 97 & $49(50.5 \%)$ & $26(26.8 \%)$ & $7(7.2 \%)$ & $15(15.5 \%)$ & $\begin{array}{l}0.70 \\
(0.47 \\
1.05)\end{array}$ & & \\
\hline & Control & 93 & $43(46.2 \%)$ & $31(33.3 \%)$ & $5(5.4 \%)$ & $14(15.1 \%)$ & $\begin{array}{l}0.67 \\
(0.47 \\
0.97)\end{array}$ & $\begin{array}{l}1.05 \\
(0.61, \\
1.80\end{array}$ & 0.87 \\
\hline \multirow[t]{2}{*}{$\begin{array}{l}\geq 20 \\
\text { MME }\end{array}$} & N-of-1 & 97 & $68(70.1 \%)$ & $15(15.5 \%)$ & $5(5.2 \%)$ & $9(9.3 \%)$ & $\begin{array}{l}0.79 \\
(0.51 \\
1.22)\end{array}$ & & \\
\hline & Control & 93 & $66(71.0 \%)$ & $16(17.2 \%)$ & $8(8.6 \%)$ & $3(3.2 \%)$ & $\begin{array}{l}1.36 \\
(0.92 \\
2.00)\end{array}$ & $\begin{array}{l}0.58 \\
(0.33 \\
1.04)\end{array}$ & 0.07 \\
\hline \multirow[t]{2}{*}{$\begin{array}{l}\geq 50 \\
\text { MME }\end{array}$} & N-of-1 & 97 & $90(93.8 \%)$ & $4(4.1 \%)$ & $1(1.0 \%)$ & $2(2.1 \%)$ & $\begin{array}{l}0.82 \\
(0.43 \\
1.59)\end{array}$ & & \\
\hline & Control & 93 & $84(90.3 \%)$ & $4(4.3 \%)$ & $4(4.3 \%)$ & $1(1.1 \%)$ & $\begin{array}{l}1.66 \\
(0.79 \\
3.47)\end{array}$ & $\begin{array}{l}0.50 \\
(0.19 \\
1.34)\end{array}$ & 0.17 \\
\hline
\end{tabular}

MME milligrams morphine equivalent, OR odds ratio, CI confidence interval, ROR relative odds ratio

*Never taking: patients not taking an opioid medication (or taking below the given dose threshold) at both baseline and 6 months

${ }^{+}$Continued taking: patients taking an opioid medication at or above the given dose threshold at both baseline and 6 months

${ }^{t}$ Started taking: patients not taking an opioid medication at baseline visit (or taking below the given dose threshold), but taking medication at or above the threshold at 6 months

${ }^{S}$ Stopped taking: patients taking an opioid medication at baseline visit (or taking above the given dose threshold), but not taking medication (or taking below the dose threshold) at 6 months

"OR refers to comparison within group of baseline vs. 6 months

\section{RESULTS}

\section{Baseline Characteristics of Participants}

The mean age of participants was 55 years (SD 11); most were Caucasian (72\%) (Table 1). Men and women were nearly equally represented (53\% versus $47 \%$ ). Fully half of the participants in the study were not currently working. There were no substantive differences between intervention (N-of-1) and control (usual care) groups in terms of demographic characteristics or average pain intensity at baseline. Intervention patients were more likely to be prescribed oral nonsteroidal anti-inflammatory drugs at baseline and somewhat less likely to be taking opioids. The majority of patients experienced mechanical pain. As previously reported, there were no significant differences in analgesic adherence between baseline and 6 months in either the intervention or control group (data not shown). ${ }^{26}$

Patients who withheld permission to abstract their medical records or who dropped out of the study prior to 6 months (and thus withdrew permission de facto) $(n=25)$ had slightly worse physical health, were more likely to be VA patients, and were more likely to have pain categorized as "other/unknown," but were otherwise comparable in demographic characteristics and pain outcomes to patients whose records were abstracted ( $n=190)$ (Online Appendix 1).

\section{Opioid Use}

Among the 97 patients assigned to the N-of-1 group and for whom medical record data were available, 7 started opioids during the 6-month follow-up period and 15 stopped
(Table 2). In comparison, among those assigned to control, 5 started opioids and 14 stopped. There was no significant between-group difference in the relative odds of any opioid use at follow-up relative to baseline (relative odds ratio [ROR] $1.05,95 \%$ CI 0.61 to $1.80, p=0.87$ ) (Table 2). Using a threshold of $20 \mathrm{MME} /$ day (the equivalent of four 5/325 hydrocodone/ acetaminophen tablets daily), fewer patients reached the threshold and more patients fell below it in the N-of-1 group (5 and 9, respectively) compared to control ( 8 and 3 , respectively) during the follow-up period, but the result was not significant ( $p=$ 0.07 ). Very few patients were prescribed $50 \mathrm{MME}$ or more per day, but results were consistent with those obtained using the $20 \mathrm{MME}$ threshold (ROR 0.50, 95\% CI 0.19 to $0.34, p=0.17$ ). In an ancillary analysis, mean MME in the intervention group decreased from 13.1 at baseline to 11.5 at 6 months; the corresponding change in the control group was from 13.4 to 15.5 (difference $-3.73 \mathrm{MME}, 95 \% \mathrm{CI}-8.96$ to $1.50, p$ value 0.16 ).

\section{Oral NSAID Use}

Among 97 patients assigned to the N-of-1 group, 8 started oral NSAIDs during the 6-month follow-up period and 23 stopped (Table 3). In comparison, among those assigned to control, 9 started NSAIDs and 9 stopped. The between-group difference in NSAID prescribing was significant (ROR 0.53, 95\% CI 0.29 to $0.97, p=0.04$ ) (Table 3 ). The number needed to treat for deprescribing NSAIDs in one individual was 6.47. Of the 23 patients assigned to the N-of-1 arm and who stopped NSAIDS between baseline and follow-up, 15 had a clinically significant ( $>3$ point) decrease in pain intensity and none had a clinically significant increase. Of the 9 patients assigned to the control 
Table 3 Change Between Baseline Visit and 6-Month Follow-Up in Use of NSAIDs and "Adjunctive Medications" (Acetaminophen, Gabapentenoids, and Topical Analgesics)

\begin{tabular}{|c|c|c|c|c|c|c|c|c|c|}
\hline & Group & Number & $\begin{array}{l}\text { Never } \\
\text { taking* }\end{array}$ & $\begin{array}{l}\text { Continued } \\
\text { taking }^{\dagger}\end{array}$ & Started $^{*}$ & Stopped $^{\S}$ & $\begin{array}{l}\text { OR } \\
(95 \% \\
\text { CI) }\end{array}$ & ROR (95\% CI) & $\begin{array}{l}p \\
\text { value }\end{array}$ \\
\hline \multirow[t]{2}{*}{$\%$ taking NSAIDs } & N-of-1 & 97 & $\begin{array}{l}40 \\
(41.2 \%)\end{array}$ & $26(26.8 \%)$ & $8(8.3 \%)$ & $\begin{array}{l}23 \\
(23.7 \%)\end{array}$ & $\begin{array}{l}0.53 \\
(0.34 \\
0.83)\end{array}$ & & \\
\hline & Control & 93 & $\begin{array}{l}52 \\
(55.9 \%)\end{array}$ & $23(24.7 \%)$ & $9(9.7 \%)$ & $9(9.7 \%)$ & $\begin{array}{l}1.00 \\
(0.67, \\
1.49)\end{array}$ & $0.53(0.29,0.97)$ & 0.04 \\
\hline \multirow[t]{2}{*}{$\begin{array}{l}\% \text { taking one or more } \\
\text { adjunctive medications }\end{array}$} & N-of-1 & 97 & $\begin{array}{l}53 \\
(54.6 \%)\end{array}$ & $27(27.8 \%)$ & $9(9.3 \%)$ & $8(8.2 \%)$ & $\begin{array}{l}1.04 \\
(0.73, \\
1.50)\end{array}$ & & \\
\hline & Control & 93 & $\begin{array}{l}55 \\
(59.1 \%)\end{array}$ & $18(19.4 \%)$ & $8(8.6 \%)$ & $\begin{array}{l}12 \\
(12.9 \%)\end{array}$ & $\begin{array}{l}0.82 \\
(0.52, \\
1.28)\end{array}$ & $1.28(0.72,2.28)$ & 0.39 \\
\hline \multirow[t]{2}{*}{$\%$ taking acetaminophen } & N-of-1 & 97 & $\begin{array}{l}81 \\
(83.5 \%)\end{array}$ & $5(5.2 \%)$ & $4(4.1 \%)$ & $7(7.2 \%)$ & $\begin{array}{l}0.72 \\
(0.36, \\
1.46)\end{array}$ & & \\
\hline & Control & 93 & $\begin{array}{l}85 \\
(91.4 \%)\end{array}$ & $3(3.2 \%)$ & $3(3.2 \%)$ & $2(2.2 \%)$ & $\begin{array}{l}1.21 \\
(0.52, \\
2.84)\end{array}$ & $0.60(0.20,1.79)$ & 0.36 \\
\hline \multirow[t]{2}{*}{$\%$ taking gabapentenoids } & N-of-1 & 97 & $\begin{array}{l}75 \\
(77.3 \%)\end{array}$ & $14(14.4 \%)$ & $6(6.2 \%)$ & $2(2.1 \%)$ & $\begin{array}{l}1.31 \\
(0.90, \\
1.92)\end{array}$ & & \\
\hline & Control & 93 & $\begin{array}{l}71 \\
(76.3 \%)\end{array}$ & $13(14.0 \%)$ & $4(4.3 \%)$ & $5(5.4 \%)$ & $\begin{array}{l}0.93 \\
(0.62, \\
1.41)\end{array}$ & $1.41(0.81,2.47)$ & 0.23 \\
\hline \multirow[t]{2}{*}{$\%$ using topicals } & N-of-1 & 97 & $\begin{array}{l}81 \\
(83.5 \%)\end{array}$ & $7(7.2 \%)$ & $6(6.2 \%)$ & $3(3.1 \%)$ & $\begin{array}{l}1.35 \\
(0.75 \\
2.41)\end{array}$ & & \\
\hline & Control & 93 & $\begin{array}{l}78 \\
(83.9 \%)\end{array}$ & $3(3.2 \%)$ & $5(5.4 \%)$ & $7(7.5 \%)$ & $\begin{array}{l}0.78 \\
(0.34 \\
1.81)\end{array}$ & $1.72(0.62,4.78)$ & 0.30 \\
\hline
\end{tabular}

OR odds ratio, CI confidence interval, ROR relative odds ratio, OR for intervention group/OR for control group

*Never taking: patients not taking specified medication at both baseline and 6 months

${ }^{+}$Continued taking: patients taking medication at both baseline and 6 months

Started: patients not taking specified medication at baseline visit, but taking at 6 months

SStopped: patients taking specified medication at baseline visit, but not taking at 6 months

"OR refers to comparison within group of baseline vs. 6 months

arm and who stopped NSAIDs, pain intensity outcomes were available for 8 , of whom 3 had a clinically significant decrease in pain and 2 had a clinically significant increase.

\section{Adjunctive Medications}

Throughout the study, more patients used gabapentoids than either acetaminophen or topicals (Table 3). Comparing the Nof-1 and control groups, there was no significant difference in use of adjunctive medications over time, whether considered collectively (ROR $1.28,95 \%$ CI 0.72 to $2.28, p=0.39$ ) or examining acetaminophen, gabapentenoids, and topicals separately ( $p=0.36,0.23$, and 0.30 , respectively) (Table 3 ).

\section{DISCUSSION}

In the treatment of chronic non-cancer pain-most of which is musculoskeletal in origin - some 5 to 8 million Americans are taking opioids, while 37 million are taking non-aspirin NSAIDs. ${ }^{37-41}$ When used for this indication, opioids and NSAIDs have limited effectiveness and well-defined adverse effects. ${ }^{1,6,42,43}$ Nevertheless, many patients starting these agents for acute painful conditions continue them, and some misuse them. ${ }^{6,44}$ We conducted the current study to determine whether participation in an N-of-1 trial could alter the likelihood that a patient would be prescribed opioids or NSAIDs 6 months from baseline compared with usual care. We also assessed whether some patients might add or switch to "adjunctive" medications with a better or at least different safety profile. We found that N-of-1 trial participation was associated with no change in adjunctive medications, significantly decreased NSAID prescriptions relative to controls, and a $42 \%$, statistically non-significant, reduction in the odds of being prescribed at least $20 \mathrm{mg}$ equivalents of morphine daily. Twenty MME per day is an arbitrary cutoff that may indicate regular daily opioid use rather than as needed ("prn") use.

The effect of N-of-1 trial participation on NSAID use is preliminary and requires confirmation in larger studies but may have implications for improved analgesic prescribing. While NSAIDs provide effective analgesia for many patients with musculoskeletal pain, they are associated with gastrointestinal bleeding, nephrotoxicity, and exacerbations of congestive heart failure, so interventions that reduce their use may enhance patient safety. ${ }^{42,}{ }^{45-47}$ Given the large number of patients worldwide taking non-aspirin NSAIDs regularly, even a modest reduction in NSAID use could result in thousands of adverse events averted. ${ }^{6}$ 
Factors associated with a higher likelihood of opioid-related suicide and/or accidental overdose include history of overdose, history of substance use disorder, concurrent benzodiazepine use, and opioid dosages of at least $50 \mathrm{MME} /$ day. $^{48}$ In our cohort, relatively few patients were taking $\geq 50 \mathrm{MME} /$ day, limiting power to observe changes over time in relation to random assignment (N-of-1 versus control). Further study in larger samples is needed to determine if the observed trend is reproducible. If confirmed, this result suggests that participation in an N-of-1 trial may help selected patients de-escalate their opioid regimens before they become intractably dependent.

We can imagine four possible mechanisms by which participation in N-of-1 trials may have resulted in less NSAID use and perhaps in less opioid use. The most straightforward explanation is that N-of-1 participants learned that NSAIDs and/or opioids were either less effective or associated with more side effects than they had previously suspected, and they requested or agreed to take an alternative regimen. ${ }^{49}$ The second possible explanation is biopsychosocial: patients participating in N-of-1 trials may have developed closer relationships with their treating clinicians, leading them to embrace their clinician's advice to stop or curtail opioids or NSAIDs. ${ }^{50}$ Third, it is possible that patients participating in N-of-1 trials become more self-aware and thus experienced pain in a different way. Finally, by utilizing the Trialist app, patients in the N-of-1 group may have acquired greater insight about alleviating and aggravating factors affecting their pain, which in turn permitted them to make adjustments to their treatment regimens on their own. This hypothesis is indirectly supported by patient interviews emphasizing the perceived value of self-management from the app's tracking functions. ${ }^{26,51}$

This study employed a strong randomized design but also has several limitations. The sample size was modest, limiting the ability to detect small to moderate effects. Although our analysis adjusted for baseline imbalances in the proportion of patients taking NSAIDs, the much higher baseline prevalence of NSAID use within the N-of-1 (intervention) group compared with control may have been associated with other, unmeasured confounders. In addition, the statistically significant decrease in NSAID use among the intervention group may simply reflect regression to the mean. Detail on adherence (such as pill counts) would have allowed us to estimate doses of analgesics actually ingested, but these data were unfortunately not available. In the opioid analysis, the $20 \mathrm{MME}$ cutoff, while clinically defensible, was not pre-specified, underscoring the preliminary nature of the results. Over-the-counter analgesic use was neither regulated nor monitored among study participants. Finally, the study was conducted in one geographic region, potentially limiting generalizability.

In this study, we found a significant decrease in NSAID use among chronic musculoskeletal pain patients randomized to participate in an N-of-1 trial (without a concomitant increase in reported pain) along with a potentially important (but not statistically significant) reduction in moderate opioid use (defined as $\geq 20 \mathrm{MME} /$ day). However, additional research is needed to develop more robust evidence on the ability of N-of-1 trials to help patients transition away from medication regimens for which the putative benefits are counterbalanced by possible harms.

\section{Acknowledgments:}

The authors thank the Scientific Advisory Board members for their valuable suggestions and recommendations on a variety of scientific issues, the study protocol, patient recruitment, retention, and adherence; Colin Barr, Sarah Benedetti, Navjot Dhammi, and Peach Dounias for their dedication and assistance with conducting patient visits, interviewing participants, and data collection activities; participating clinicians and medical staff at the University of California Davis Primary Care Network, and Veterans Affairs Northern California Health Care System at Mather and McClellan Medical Centers for their efforts in patient recruitment and assisting patients completing $N$-of-1 trials; and study participants whose cooperation, commitment, and enthusiasm were critical to the study's success.

Disclaimer: The contents of this article are solely the responsibility of the authors and do not represent the views of the United States Government, United States Army, or Department of Veterans Affairs.

Corresponding Author: Richard L. Kravitz, MD, MSPH; Department of Internal Medicine, Division of General Medicine University of California Davis, Sacramento, CA, USA (e-mail: rlkravitz@ucdavis. edu).

Funding Information This research was supported by the National Institute of Nursing Research (1RO1NR013938) and the National Center for Advancing Translational Sciences (NCATS), National Institutes of Health (NIH), through grant UL1 TR000002. Additional support through resources and the use of facilities was provided by Veterans Affairs, Northern California Health Care System (VANCHCS) at Mather and McClellan Medical Centers.

\section{Compliance with Ethical Standards:}

Conflict of Interest: The authors declare that they do not have a conflict of interest.

\section{REFERENCES}

1. Babatunde OO, Jordan JL, Van der Windt DA, Hill JC, Foster NE, Protheroe $\mathbf{J}$. Effective treatment options for musculoskeletal pain in primary care: a systematic overview of current evidence. PLoS One. 2017;12(6):e0178621.

2. Krebs EE, Gravely A, Nugent S, Jensen AC, DeRonne B, Goldsmith ES, et al. Effect of opioid vs nonopioid medications on pain-related function in patients with chronic back pain or hip or knee osteoarthritis pain: the SPACE Randomized Clinical Trial. JAMA. 2018;319(9):872-82.

3. Dowell D, Haegerich TM, Chou R. CDC Guideline for Prescribing Opioids for Chronic Pain-United States, 2016. MMWR Recomm Rep. 2016;65(1): 1-49.

4. Wiese A, Griffin M, Schaffner W, Stein M, Greevy R, Mitchel E, et al. Opioid analgesic use and risk for invasive pneumococcal diseases: a nested case-control study. Ann Intern Med. 2018;168(6):396-404.

5. DiJulio B, Wu B, Brodie $\mathbf{M}$. The Washington Post/Kaiser Family Foundation Survey of Long-Term Prescription Painkiller Users and Their Household Members. The Henry J. Kaiser Family Foundation, 2016 December. Report No.: Contract No.: 8942. 
6. Chou R, Turner JA, Devine EB, Hansen RN, Sullivan SD, Blazina I, et al. The effectiveness and risks of long-term opioid therapy for chronic pain: a systematic review for a National Institutes of Health Pathways to Prevention Workshop. Ann Intern Med. 2015;162(4):276-86.

7. Welsch $\mathbf{P}$, Sommer C, Schiltenwolf $\mathbf{M}$, Hauser $\mathbf{W}$. Opioids in chronic noncancer pain-are opioids superior to nonopioid analgesics? A systematic review and meta-analysis of efficacy, tolerability and safety in randomized head-to-head comparisons of opioids versus nonopioid analgesics of at least four week's duration. Schmerz (Berlin, Germany). 2015;29(1):85-95.

8. Chang AK, Bijur PE, Esses D, Barnaby DP, Baer J. Effect of a single dose of oral opioid and nonopioid analgesics on acute extremity pain in the emergency department: a randomized clinical trial. JAMA. 2017;318(17):1661-7.

9. Bally M, Dendukuri N, Rich B, Nadeau L, Helin-Salmivaara A, Garbe $\mathbf{E}$, et al. Risk of acute myocardial infarction with NSAIDs in real world use: Bayesian meta-analysis of individual patient data. Bmj. 2017;357:j1909.

10. Bannuru RR, Schmid CH, Kent DM, Vaysbrot EE, Wong JB, McAlindon TE. Comparative effectiveness of pharmacologic interventions for knee osteoarthritis: a systematic review and network metaanalysis. Ann Intern Med. 2015;162(1):46-54.

11. Arfe A, Scotti L, Varas-Lorenzo C, Nicotra F, Zambon A, Kollhorst B, et al. Non-steroidal anti-inflammatory drugs and risk of heart failure in four European countries: nested case-control study. Bmj. 2016;354:i4857.

12. Sondergaard $\mathbf{K B}$, Weeke $\mathbf{P}$, Wissenberg $\mathbf{M}$, Schjerning Olsen AM, Fosbol EL, Lippert FK, et al. Non-steroidal anti-inflammatory drug use is associated with increased risk of out-of-hospital cardiac arrest: a nationwide case-time-control study. Eur Heart J Cardiovasc Pharmacotherapy. 2017;3(2):100-7.

13. Trelle $\mathbf{S}$, Reichenbach $\mathbf{S}$, Wandel $\mathbf{S}$, Hildebrand $\mathbf{P}$, Tschannen $\mathbf{B}$ Villiger PM, et al. Cardiovascular safety of non-steroidal anti-inflammatory drugs: network meta-analysis. Bmj. 2011;342:c7086.

14. Nelson DA, Marks ES, Deuster PA, O'Connor FG, Kurina LM. Association of nonsteroidal anti-inflammatory drug prescriptions with kidney disease among active young and middle-aged adults. JAMA Netw Open. 2019;2(2):e187896.

15. Rios R, Zautra AJ. Socioeconomic disparities in pain: the role of economic hardship and daily financial worry. Health Psychol. 2011;30(1):58-66.

16. Timmermans EJ, Schaap LA, Herbolsheimer F, Dennison EM, Maggi $\mathbf{S}$, Pedersen NL, et al. The influence of weather conditions on joint pain in older people with osteoarthritis: results from the European Project on OSteoArthritis. J Rheumatol. 2015;42(10):1885-92.

17. Timmermans EJ, van der Pas S, Schaap LA, Sanchez-Martinez M, Zambon S, Peter R, et al. Self-perceived weather sensitivity and joint pain in older people with osteoarthritis in six European countries: results from the European Project on OSteoArthritis (EPOSA). BMC Musculoskelet Disord. 2014;15:66.

18. Lee M, Ohde S, Urayama K, Takahashi O, Fukui T. Weather and health symptoms. Int J Environ Res Public Health. 2018;15(8):1670.

19. Smith DM, Brown SL, Ubel PA. Mispredictions and misrecollections: challenges for subjective outcome measurement. Disabil Rehabil. 2008;30(6):418-24.

20. Zucker DR, Ruthazer R, Schmid CH, Feuer JM, Fischer PA, Kieval RI, et al. Lessons learned combining N-of-1 trials to assess fibromyalgia therapies. J Rheumatol. 2006;33(10):2069-77.

21. Kravitz RL. Personalized medicine without the "omics". J Gen Intern Med. 2014;29(4):551.

22. Labianca $\mathbf{R}$, Sarzi-Puttini $\mathbf{P}$, Zuccaro SM, Cherubino $\mathbf{P}$, Vellucci $\mathbf{R}$ Fornasari D. Adverse effects associated with non-opioid and opioid treatment in patients with chronic pain. Clin Drug Investig. 2012;32 Suppl 1:53-63.

23. Greenfield S, Kaplan S, Ware JE Jr. Expanding patient involvement in care. Effects on patient outcomes. Ann Intern Med. 1985;102(4):520-8.

24. Greene J, Hibbard JH, Sacks R, Overton V, Parrotta CD. When patient activation levels change, health outcomes and costs change, too. Health Aff. 2015;34(3):431-7.

25. Barr C, Marois M, Sim I, Schmid CH, Wilsey B, Ward D, et al. The PREEMPT Study - evaluating smartphone-assisted N-of-1 trials in patients with chronic pain: study protocol for a randomized controlled trial. Trials. 2015;16:67.

26. Kravitz RL, Schmid CH, Marois M, Wilsey B, Ward D, Hays RD, Duan N, Wang Y, MacDonald S, Jerant A, Servadio JL. Effect of mobile devicesupported single-patient multi-crossover trials on treatment of chronic musculoskeletal pain: a randomized clinical trial. JAMA Intern Med. 2018;178(10): 1368-77.

27. Chou R, Deyo R, Friedly J, Skelly A, Weimer M, Fu R, et al. Systemic pharmacologic therapies for low back pain: a systematic review for an American College of Physicians Clinical Practice Guideline. Ann Intern Med. 2017;166(7):480-92.

28. Moore RA, Derry S, Wiffen PJ, Straube S, Aldington DJ. Overview review: comparative efficacy of oral ibuprofen and paracetamol (acetaminophen) across acute and chronic pain conditions. Eur J Pain. 2015;19(9): 1213-23.

29. Shanthanna H, Gilron I, Rajarathinam M, AlAmri R, Kamath S, Thabane $\mathbf{L}$, et al. Benefits and safety of gabapentinoids in chronic low back pain: a systematic review and meta-analysis of randomized controlled trials. PLoS Med. 2017;14(8):e1002369.

30. Derry S, Wiffen PJ, Kalso EA, Bell RF, Aldington D, Phillips T, et al. Topical analgesics for acute and chronic pain in adults-an overview of Cochrane Reviews. Cochrane Database Syst Rev. 2017;5:CD008609.

31. Gudin JA, Brennan MJ, Harris ED, Hurwitz PL, Dietze DT, Strader JD. Reduction of opioid use and improvement in chronic pain in opioidexperienced patients after topical analgesic treatment: an exploratory analysis. Postgrad Med. 2018;130(1):42-51.

32. Derry S, Conaghan P, Da Silva JA, Wiffen PJ, Moore RA. Topical NSAIDs for chronic musculoskeletal pain in adults. Cochrane Database Syst Rev. 2016;4:CD007400.

33. Krebs EE, Lorenz KA, Bair MJ, Damush TM, Wu J, Sutherland JM, et al. Development and initial validation of the PEG, a three-item scale assessing pain intensity and interference. $J$ Gen Intern Med. 2009;24(6):733-8.

34. Personalized Research for Monitoring Pain Treatment (PREEMPT). health. ucdavis.edu: Center for Healthcare Policy and Research; 2019 [19 June 2019]; Available from: https://health.ucdavis.edu/chpr/preempt.

35. Dima AL, Dediu D. Computation of adherence to medication and visualization of medication histories in $\mathrm{R}$ with AdhereR: towards transparent and reproducible use of electronic healthcare data. PLoS One. 2017;12(4):e0174426.

36. Von Korff M, Saunders K, Thomas Ray G, Boudreau D, Campbell C, Merrill J, et al. De facto long-term opioid therapy for noncancer pain. Clin J Pain. 2008;24(6):52 1-7.

37. Reuben DB, Alvanzo AA, Ashikaga T, Bogat GA, Callahan CM, Ruffing $\mathbf{V}$, et al. National Institutes of Health Pathways to Prevention Workshop: the role of opioids in the treatment of chronic pain. Ann Intern Med. 2015;162(4):295-300.

38. Boudreau D, Von Korff M, Rutter CM, Saunders K, Ray GT, Sullivan MD, et al. Trends in long-term opioid therapy for chronic non-cancer pain. Pharmacoepidemiol Drug Saf. 2009;18(12):1166-75.

39. Sullivan MD, Edlund MJ, Fan MY, Devries A, Brennan Braden J, Martin BC. Trends in use of opioids for non-cancer pain conditions 20002005 in commercial and Medicaid insurance plans: the TROUP study. Pain. 2008; 138(2):440-9.

40. Guy GP Jr., Zhang K, Bohm MK, Losby J, Lewis B, Young R, et al. Vital signs: changes in opioid prescribing in the United States, 2006-2015. MMWR Morb Mortal Wkly Rep. 2017;66(26):697-704.

41. Davis JS, Lee HY, Kim J, Advani SM, Peng HL, Banfield E, et al. Use of non-steroidal anti-inflammatory drugs in US adults: changes over time and by demographic. Open Heart. 2017;4(1):e000550.

42. Schneider V, Levesque LE, Zhang B, Hutchinson T, Brophy JM. Association of selective and conventional nonsteroidal antiinflammatory drugs with acute renal failure: a population-based, nested case-control analysis. Am J Epidemiol. 2006;164(9):881-9.

43. Wehling M. Non-steroidal anti-inflammatory drug use in chronic pain conditions with special emphasis on the elderly and patients with relevant comorbidities: management and mitigation of risks and adverse effects. Eur J Clin Pharmacol. 2014;70(10):1159-72.

44. Kaufman DW, Kelly JP, Battista DR, Malone MK, Weinstein RB, Shiffman S. Exceeding the daily dosing limit of nonsteroidal antiinflammatory drugs among ibuprofen users. Pharmacoepidemiol Drug Saf. 2018;27(3):322-31.

45. Rasmussen-Barr E, Held U, Grooten WJ, Roelofs PD, Koes BW, van Tulder MW, et al. Non-steroidal anti-inflammatory drugs for sciatica. Cochrane Database Syst Rev.. 2016;10:Cd012382.

46. Huerta C, Castellsague J, Varas-Lorenzo C, Garcia Rodriguez LA. Nonsteroidal anti-inflammatory drugs and risk of ARF in the general population. Am J Kidney Dis. 2005;45(3):531-9.

47. Gooch K, Culleton BF, Manns BJ, Zhang J, Alfonso H, Tonelli M, et al. NSAID use and progression of chronic kidney disease. Am J Med.. 2007;120(3):280.e1-7. 
48. Dowell D, Haegerich TM, Chou R. CDC Guideline for Prescribing Opioids for Chronic Pain-United States, 2016. JAMA. 2016;315(15):1624-45.

49. Spicer CC. Statistical decision theory and clinical trials. Br J Clin Pharmacol. 1982;14(6):765-8.

50. Davis MS. Variations in patients' compliance with doctors' advice: an empirical analysis of patterns of communication. Am J Public Health Nations Health. 1968;58(2):274-88.
51. Whitney RL, Ward DH, Marois MT, Schmid CH, Sim I, Kravitz RL. Patient perceptions of their own data in mhealth technology-enabled Nof- 1 trials for chronic pain: qualitative study. JMIR Mhealth Uhealth. 2018;6(10):e10291.

Publisher's Note Springer Nature remains neutral with regard to jurisdictional claims in published maps and institutional affiliations. 